\title{
ARTÍCULO
}

\section{Imperativos, normas y verdad \\ Imperatives, norms and truth.}

\author{
Antonio Ibáñez Macías \\ Facultad de Derecho \\ Universidad de Cádiz
}

Fecha de recepción 28/06/2018 | De aceptación: 19/11/2018 | De publicación: 24/12/2018

\section{RESUMEN.}

Antes de emprender el análisis lógico de las normas jurídicas constitucionales, o de las normas en general, es preciso intentar resolver una cuestión previa que afecta a la posibilidad de existencia de una lógica de las normas: el dilema de Jørgensen. Nuestra propuesta de solución de este dilema es la siguiente: las normas son expresiones performativas. Al mismo tiempo, las expresiones performativas son enunciados que tienen valor de verdad. Además, las normas jurídicas son enunciados del tipo "A dice p", lo que explica que puedan existir normas verdaderas y, al mismo tiempo, contradictorias entre sí.

\section{PALABRAS CLAVE.}

Imperativos, normas, verdad, dilema de Jørgensen.

\section{ABSTRACT.}

Before embarking on the logical analysis of constitutional legal norms or norms in general, it is necessary to try to resolve a previous question that affects the possibility of the existence of a logic of norms: the Jørgensen's dilemma. Our proposed solution to this dilemma is as follows: norms are performative utterances. At the same time, performative utterances are statements that have truth value. In addition, the legal norms are statements of type "A says p", which explains that there may be true norms and, at the same time, contradictory to each other.

\section{KEY WORDS.}

Imperatives, norms, truth, Jørgensen's dilemma. 
Índice: 1. Introducción. El dilema de Jørgensen; Los imperativos y normas como enunciados performativos; 2.1. Los imperativos; 2.2. Las normas; 3. Imperativos y normas como enunciados del tipo "A dice p"; 4. El valor de la verdad de los enunciados perfomativos; 4.1. La verificación de la verdad de los imperativos; 4.2. La verificación de la verdad de las normas; 5. Normas verdaderas y relaciones lógicas entre normas; 6. Bibliografía.

\section{Introducción. El dilema de Jørgensen.}

En 1938 el filósofo danés Jørgen Jørgensen sostuvo, en sendos artículos titulados Imperatives and logic, e Imperativer og Logik, que no es posible realizar inferencias lógicas con enunciados imperativos. Esto implica, si se incluyen las normas entre los imperativos en sentido amplio (como enunciados de deber), que no son posibles las relaciones lógicas entre normas, ya sean éstas morales o jurídicas. Dicho de otro modo, es imposible aplicar la lógica (incluida la lógica simbólica) a los enunciados jurídicos normativos. Y sin embargo, lo hacemos. Ese es “el dilema de Jørgensen”, tal como lo denominó Alf Ross (Ross 1941, 53-71).

El razonamiento de Jørgensen es el siguiente:

Premisa Mayor: Carácter apofántico de los enunciados (es decir, que puedan ser verdaderos o falsos) como condición necesaria para que exista relación de consecuencia lógica entre enunciados.

En efecto, de acuerdo con la noción de consecuencia lógica, "la conclusión se sigue lógicamente de las premisas (o sea, es consecuencia lógica de las premisas) si, y solo si, está excluido que las premisas puedan ser verdaderas y la conclusión falsa (en otros términos: si, y solo si, está excluida la posibilidad de que las premisas sean verdaderas y la conclusión sea falsa)" [Jørgensen 1999 (1938)1, 211 ].

Premisa Menor: Carácter no apofántico (es decir, que no son ni verdaderos ni falsos) de los enunciados imperativos.

Conclusión: Imposibilidad de que entre los enunciados imperativos medien relaciones de consecuencia lógica. "Así pues, los enunciados imperativos no pueden aparecer en inferencias lógicas ni como premisas ni como conclusiones" [Jørgensen 1999 (1938), 212].

1 Cuando consultamos una obra traducida al castellano, ponemos entre paréntesis el año de la edición en idioma original. 
Aplicando a las normas jurídicas esta teoría ${ }^{2}$, podríamos decir que "si y solo si las normas jurídicas tienen valor de verdad $(A)$, entonces existen relaciones lógicas entre las normas jurídicas $(B)$ ". Expresado en lógica proposicional sería: $A \leftrightarrow B$

De aquí podemos deducir, por ejemplo, que "las normas jurídicas carecen de valor de verdad, y entonces no existen relaciones lógicas entre normas jurídicas" ( $\sim \mathrm{A} \rightarrow \sim \mathrm{B}$ ) (tesis de Jørgensen), o bien que "las normas poseen valor de verdad y, entonces, existen relaciones lógicas entre normas" $(A \rightarrow B)$, o la inversa, que "existen relaciones lógicas entre normas y, entonces, las normas poseen valor de verdad" (B $\rightarrow$ A). Pero, a partir de la premisa $A \leftrightarrow B$ no puede inferirse: "las normas tienen valor de verdad, y entonces no existen relaciones lógicas entre normas" (A $\rightarrow \sim \mathrm{B})$, o "las normas no tienen valor de verdad, $\mathrm{y}$ entonces existen relaciones lógicas entre normas" "( $\sim \mathrm{A} \rightarrow \mathrm{B})$.

Si aceptamos que la conclusión del razonamiento de Jørgensen es verdadera, entonces, consecuentemente, deberíamos dejar de realizar inferencias lógicas con normas. Pero si seguimos realizando tales inferencias, debemos admitir que la conclusión de Jørgensen es falsa, y por tanto, alguna de sus premisas es falsa, la premisa mayor o la menor, o ambas.

Nuestra propuesta de solución consiste en negar la premisa menor y, por tanto, afirmar el valor de verdad de los imperativos y normas.

\section{Los imperativos y normas como enunciados performativos.}

\subsection{Los imperativos.}

Dice Jørgen Jørgensen que "los enunciados imperativos son enunciados en los cuales el modo del verbo principal es el modo imperativo" [Jørgensen 1999 (1938), 212]. De acuerdo con esto, una norma jurídica, que no usa verbos en imperativo, no es un imperativo. Y por tanto, su famoso dilema no sería aplicable a las normas jurídicas.

Pero supongamos que las normas, entendidas como enunciados de "deber", son imperativos. De hecho, son prescripciones, como veremos después. Respecto de los enunciados imperativos en sentido estricto dice Jørgensen que:

2 Para una defensa de la existencia, de la posibilidad y de la utilidad de una lógica de los imperativos, véase: Vranas 2010. 
"Los enunciados imperativos que expresan una orden o un mandato son meras señales como 'Calla', ‘¡Atentos!', 'Descansen’, ‘¡Marchen!'. Son meras señales (eventualmente sustituibles con un simple gesto) que se usan para provocar determinadas acciones en individuos convenientemente adiestrados.

Con frecuencia, estos enunciados funcionan de modo puramente sugestivo, pero, en todos los casos, la relación que media entre ellos y la acción que el autor del mandato quiere provocar en el destinatario del mandato difiere de la relación representativa que media entre un enunciado indicativo y el argumento que el enunciado indicativo describe.

Por ello, enunciados imperativos de este tipo no pueden entrar como términos, como miembros en inferencias lógicas: no pueden ni ser fundados lógicamente, ni ser usados para dar fundaciones lógicas” [Jørgensen 1999 (1938), 213 y 214].

En nuestra opinión, estos enunciados prescriptivos no solo intentan influir en la conducta ajena, sino que también transmiten una información y, por tanto, tienen también un contenido indicativo. La propuesta de solución de Jørgensen a su propio dilema consiste, precisamente, en distinguir en los enunciados imperativos un factor imperativo y un factor descriptivo, esto es, entre la prescripción y su objeto o contenido (Jørgensen 1938, 291). En nuestra opinión, no es posible realizar una separación tajante entre lo indicativo y lo prescriptivo, como veremos más adelante.

Afirmamos, además, que los imperativos y normas tienen valor de verdad. Pero ¿cuál es el valor de verdad de un imperativo? ¿Cuál es el valor de verdad del enunciado (es un ejemplo ya clásico): “¡Cierra la puerta!”?

Es preciso darse cuenta de que el enunciado E1: “¡Cierra la puerta!”, de estilo directo, tiene el mismo significado que el enunciado E2, de estilo indirecto: "Te ordeno que cierres la puerta". Ambos enunciados son equivalentes ${ }^{3}$, aunque el segundo se exprese en verbo indicativo y no en modo imperativo, puesto que el enunciado mantiene su significado: tanto la fuerza locutiva de transmitir una información (que se trata de una orden con un determinado contenido), como su fuerza ilocutiva directiva (la de intentar conseguir que el oyente haga algo) ${ }^{4}$. Habría que matizar, con Lyons, que el

3 En el mismo sentido, Peña 2006, 123.

4 En cambio, la fuerza perlocutiva de producir un efecto en el oyente no forma parte necesaria del significado del enunciado, y no es un 
enunciado El es más impreciso (su significado puede ser una orden, pero también una súplica), en cambio el enunciado E2 es más explícito (Lyons 1977, 728). Sin embargo, podemos añadir que el significado del enunciado El será, en todo caso, de carácter directivo, y su sentido preciso vendrá determinado por el contexto (Hemos supuesto que se trata de una orden). El enunciado E2 viene a concretar uno de los posibles sentidos del enunciado E1 (una orden). Pero una vez precisado su significado, mediante el análisis lingüístico, ya podemos someter el enunciado a un análisis lógico, para determinar su verdad o falsedad y sus consecuencias lógicas.

Hay que precisar que la fuerza ilocutiva de un enunciado es imprescindible para la comunicación humana, pero no para la lógica formal, que es un lenguaje artificial. De hecho, cuando la lógica formal emplea operadores deónticos (permitido, prohibido, obligatorio), los usa fuera del contexto de la comunicación humana (entre un emisor y un receptor, por ejemplo), y por ello, los despoja de toda fuerza ilocutiva. Incluso es posible aplicar a los imperativos y normas la lógica simbólica clásica (proposicional, de predicados, relacional) sin necesidad de usar operadores deónticos, haciendo abstracción del propósito ilocutivo del enunciado y quedándose solo con el aspecto locutivo.

Volviendo a nuestro ejemplo, el enunciado: “Te ordeno que cierres la puerta" es un enunciado de carácter prescriptivo expresado con un verbo en presente de indicativo. A estos actos de habla por los que la acción se realiza por medio del mismo enunciado que se emite ("juro", "bautizo", "lego", “prometo", “ordeno", “pregunto”, etc) John Austin [1982 (1962), 44 ss.] los llama enunciaciones o emisiones performativas o realizativas (performative utterances) ${ }^{5}$. El carácter performativo de estas expresiones puede venir explicitado por su propia estructura gramatical (se usa un verbo en primera persona del singular del indicativo), o puede estar implícito si la expresión gramatical es "reducible, expansible o analizable de tal modo que se obtuviera una forma en primera persona del singular del presente de indicativo en voz activa" [Austin 1982 (1962), 105]. Así hemos procedido al pasar del enunciado: “¡Cierra la puerta!” al equivalente: "Te ordeno que cierres la puerta”.

Estos enunciados consisten en un verbo performativo usado en primera persona del presente de indicativo con un complemento directo (una proposición) (Searle y Vanderveken 1985, 3). La

acto esencialmente lingüístico. Al respecto, Searle y Vanderveken 1985, 12. Para la distinción entre acto locutivo, ilocutivo y perlocutivo, como actos que se realizan simultáneamente al emitirse un enunciado, véase Austin 1982 (1962), 138 y ss. Sobre las cinco clases de propósitos ilocutivos (illocucionary points), véase Searle y Vanderveken 1985, 36-38 y $52 .$.

5 Las palabras "performativo" y "realizativo" no figuran, por ahora, en el diccionario de la RAE. Usaremos indistintamente una u otra a lo largo de este trabajo. 
estructura lógica de estos enunciado es $F(p)$ donde F representa el verbo performativo con determinada fuerza ilocutiva (afirmar, preguntar, ordenar, prometer, etc.) y "p" representa la proposición subordinada al verbo principal, es decir, el contenido proposicional. (Searle y Vanderveken 1985, 8).

Puede ocurrir que la estructura gramatical parezca indicar un acto de habla cuando en realidad significa otro diferente. Por ejemplo, el enunciado: “¿Quieres cerrar la puerta?”, parece indicar una pregunta pero realmente es un acto performativo de carácter directivo que pide u ordena a alguien que cierre la puerta (Se trata de un acto de habla indirecto: Searle y Vanderveken, 1985:10). También un simple gesto, hecho a una persona y señalando la puerta, puede significar: "Te ordeno que cierres la puerta". Lo importante para nosotros es que la expresión literal del enunciado- o incluso el gesto- pueda ser traducida (porque signifiquen lo mismo) a un enunciado performativo de carácter directivo, y, especialmente, prescriptivo.

\subsection{Las normas.}

Una prescripción directa es una prescripción emitida por un "yo" a un "tú" o a un "vosotros" o a un “nosotros"), por ejemplo: “Cerremos la puerta" equivale a "Yo ordeno que cerremos la puerta".

La lógica simbólica clásica es un lenguaje artificial riguroso pero limitado que no distingue las personas del verbo. Consideraremos los siguientes enunciados:

E1: "Yo (A) te ordeno a ti (B) que $p$ ".

E2. “Tú (A) me ordenas a mí (B) que $p$ ”.

E3: "Él (A) te ordena a ti (B) que p".

Todos estos enunciados (E1, E2, E3) se refieren al mismo hecho H, consistente en la emisión por parte de A de un enunciado E dirigido a B cuyo significado es "Yo (A) te ordeno a ti (B) que p". En E1, predomina lo prescriptivo sobre lo indicativo. E2 tiene un extraño carácter informativo: $B$ parece querer cerciorarse de la orden dada por A; el enunciado parece tener el sentido de una pregunta (esto dependerá del contexto). Si el verbo estuviera en pasado pretendería recordar a $A$ que éste le dio una orden (que a lo mejor B ya ha ejecutado). En el enunciado E3, alguien transmite a $B$ una orden dada por otro. Tiene un carácter informativo- prescriptivo.

La lógica simbólica clásica tampoco distingue los tiempos verbales. Consideremos el siguiente enunciado: E4: "Yo (A) te he ordenado a ti (B) que $p$ ". 
En el enunciado E4, $A$ intenta hacer recordar a $B$ una orden anteriormente dada. El enunciado E4 parece tener un sentido indicativo o descriptivo. ¿Pero por qué $A$ se lo recuerda a $B$ ? ¿Será porque éste todavía no ha cumplido la orden y pretende que la cumpla? En este caso el enunciado tendría un significado también prescriptivo. Fuera de contexto no sabemos darle un significado preciso a E4. En todo caso, E4 se sigue refiriendo al mismo hecho H consistente en la emisión del enunciado E1.

Lo que queremos poner de relieve es que, en los anteriores enunciados, la lógica no distingue entre sentido prescriptivo o descriptivo de un enunciado. Puesto que la sintaxis, la forma lógica, de todos los enunciados anteriores (sean prescriptivos o descriptivos a nivel de uso del lenguaje) es la misma, no tiene sentido, a la hora de efectuar el análisis lógico, mantener la distinción entre enunciados asertivos y prescriptivos. Por tanto, la separación tajante entre imperativos y enunciados descriptivos de imperativos, o entre normas y proposiciones descriptivas de normas, puede ser útil a nivel de uso del lenguaje, o para desarrollar una lógica de las "proposiciones normativas"6 pero no necesariamente para el análisis lógico de los enunciados performativos de carácter prescriptivo.

Una vez que sabemos que un enunciado tiene carácter prescriptivo (por ejemplo, por tratarse de una norma contenida en un texto jurídico), podemos aplicarle la formulación lógica.

Todos los enunciados anteriores (E1, E2, E3 y E4), cuya estructura es similar -“Ordenar que p"significan para la lógica lo mismo. "Es obligatorio p", es decir, en el lenguaje de lógica deóntica: $O P$; en lógica de los actos ilocutivos de Searle: $F(P)$. Su sentido se capta mejor mediante el uso de la lógica relacional: sea " $x$ " la persona que da la orden; "y" la que la recibe; "p" el contenido u objeto de la orden (la llamamos "p" porque es una proposición, que debe contener como mínimo un verbo); y sea “O” la prescripción cuyo significado es “ordenar". Entonces podemos decir (prescindiendo de cuantificadores) que: $x O y(p)$. Se lee: ““ $x$ ' ordena a 'y' 'p”” (por ejemplo, cerrar la puerta).

E1 hecho de que los enunciados E1, E2, E3 y E4 signifiquen lo mismo para la lógica no afecta al valor de verdad de las prescripciones, porque, como mostraremos, el enunciado prescriptivo E1 es apofántico, y los enunciados informativos- prescriptivos como E3, o que parecen simplemente informativos como E2 o E4, nunca plantearon dudas teóricas en cuanto a su valor de verdad.

6 Véase al respecto: Alchourrón y Bulygin 1987 (1971), 256 ss. 
Para poder expresarlas como enunciados performativos, podemos partir, por ahora, de la presunción de considerar las prescripciones como órdenes dadas por un “yo". Las prescripciones pueden ser directas o indirectas. La prescripción directa adoptaría esta forma: "(Yo) Ordenar (a mí, a ti, usted, vosotros, ustedes, nosotros) (p)". En cambio una prescripción indirecta, en sentido estricto, adopta la forma: “(Yo) Ordenar (a él, ella, ellos, ellas) (p)". Las normas jurídicas escritas son prescripciones indirectas de este tipo, aunque, en algunos casos, también pueden entenderse dirigidas a un "vosotros" o incluso a un "nosotros", en cuyo caso serían prescripciones directas.

Pero en determinados contextos, como el de la aplicación del derecho, la transmisión de una orden (o norma) dada por otro debe considerarse también como una prescripción indirecta en sentido amplio. Es decir, el enunciado E3 arriba mencionado es una prescripción indirecta de este tipo.

Kelsen considera que este tipo de enunciados no son normas, sino proposiciones descriptivas de normas (enunciados sobre normas), y que en ellas la palabra "deber" no tiene significado prescriptivo sino descriptivo [Kelsen 1994 (1979), 157 y 158]. Pero si la palabra “deber”, o como en nuestro ejemplo "ordenar", no tuviera un significado prescriptivo en el enunciado E3, no se podría transmitir una orden dada por un tercero, que es de lo que se trata. Cuando, como en el caso del ejemplo, se transmite una orden dada por otro es para que se cumpla. Por lo que, en estos casos, este tipo de enunciados tienen un carácter no solo informativo, sino también prescriptivo (tienen la fuerza ilocutiva propia de una prescripción).

Para transmitir la orden dada por otro es preciso referirse a ese otro en tercera persona. Como una norma jurídica es una orden dada por otro (una prescripción indirecta), el juez o aplicador del derecho solo puede referirse a quien da la orden en tercera persona, diciendo: "La autoridad ordena que...", o bien, por metonimia, "La norma (o el precepto, o la ley) ordena (o establece, dispone, prescribe, etc.) que...”. Si consideramos que estas expresiones no son prescripciones indirectas, entonces estaremos afirmando que ni el juez ni nadie aplican normas, sino enunciados sobre normas (proposiciones descriptivas de normas). Si esto es así, en ningún momento se aplica el derecho. Esta conclusión es absurda: al aplicar el derecho nadie aplica el derecho. Por tanto, en un contexto de aplicación del derecho, estas expresiones tienen un marcado sentido prescriptivo (conservan su fuerza ilocutiva).

Las normas jurídicas escritas son prescripciones indirectas en sentido estricto (esto es, dadas por un yo a terceras personas) y por tanto, pueden ser reconducidas a proposiciones del tipo "Yo ordeno $p$ ". 
Los verbos usados en estos enunciados ("se debe", "se prohíbe", "se permite") son todos reconducibles a "yo ordeno". Así, la obligación puede expresarse como "yo ordeno $p$ ”, es decir: $O(p)^{7}$. La prohibición puede expresarse como "yo prohíbo p" $\left[V^{8}(p)\right]$, esto es, "yo ordeno que no $p$ ”: $O(\sim p)$.La permisión puede entenderse como "yo permito p", dicho de otro modo, "yo no ordeno que no p": $\sim$ O ( p).

Realmente no es necesario realizar estas operaciones desde el momento en que captamos que los enunciados que contienen las expresiones "se debe", "se permite", "se prohíbe" (o sus equivalentes "es obligatorio", "está permitido", "está prohibido"), dichas en el contexto de un texto jurídico, son enunciados en sí mismo performativos, con el valor de verdad propio de este tipo de enunciados. En efecto, como apunta Austin [1982 (1962), 105] puede haber enunciados performativos emitidos en tercera persona: "Por la presente, se autoriza..." (o "se ordena", "se prohíbe", "se permite", etc.) . Pues bien, todos los enunciados jurídicos normativos escritos son performativos en este sentido: incluyen la cláusula implícita: "Por la presente" . Primero, se insertan en un texto que se presenta a sí mismo con el nombre de ley [o Constitución, etc.]. Segundo, el carácter performativo de los enunciados normativos se ve con claridad en las fórmulas rituales de promulgación de las leyes. En el caso español estas fórmulas dicen lo siguiente (las cursivas son nuestras): “(...), a todos los que la presente vieren [percepción]) y entendieren [comprensión], Sabed: Que las Cortes Generales han aprobado y Yo vengo en sancionar la siguiente Ley". Y al final del texto se añade: "Por tanto, mando [claro enunciado performativo] a todos los españoles, particulares y autoridades, que guarden y hagan guardar esta Ley”.

\section{Imperativos y normas como enunciados del tipo "A dice p".}

Además, estos enunciados de carácter performativo prescriptivo ("Yo ordeno p"), o descriptivoprescriptivo (“A ordena $p$ ”) podemos incluirlos dentro de la categoría general de enunciados del tipo "A dice p", ya estudiados, desde un punto de vista lógico, por Russell y Wittgenstein. De hecho el

$7 \quad$ En esta fórmula, la proposición " $p$ " se pone entre paréntesis porque es una proposición subordinada a la proposición principal: $O(p)$. A su vez, la proposición "p" podría ser desglosada de acuerdo con el lenguaje de la lógica de predicados o de la lógica de relaciones, según el caso, pero no es necesario hacerlo a los fines de este estudio.

8 "V" de vetar, prohibir.

9 En este sentido, Hilpinen 2006, 236. En el mismo sentido, Lorenzo Peña considera que las expresiones "Es imperativo que...” y "Es obligatorio que..." tienen carácter performativo (Peña 2006, 126). 
enunciado "Te ordeno que cierres la puerta" podemos transformarlo en "Te digo que cierres la puerta", prescindiendo de su propósito ilocutivo específico. (Aquí el mantenimiento de fuerza ilocutiva del enunciado dependerá de factores externos al propio enunciado: la entonación, la expresión corporal del hablante, etc.").

Este tipo de proposiciones del tipo "A dice p" son similares a lo que Bertrand Russell llamó "actitudes proposicionales". En palabras de Tomasini, son "esas proposiciones que contienen dos verbos, uno de los cuales es un verbo 'psicológico', i. e., verbos como 'creer', 'pensar', 'imaginar', 'dudar', 'decir' y demás”. (Tomasini 2003, 12). Nosotros podríamos añadir los verbos como "preguntar”, “ordenar”, “disponer", "prohibir”, "permitir”, etc. ${ }^{10}$ Estos verbos no son, necesariamente, psicológicos, por lo que podríamos llamar a este tipo de oraciones (del tipo “A dice p") "proposiciones supraordinadas”, porque se componen de un verbo principal al que se subordina otro, o si se prefiere, de una proposición principal (supraordinada) a la que se subordina otra (subordinada).

Lo importante de este tipo de proposiciones es que su verdad no depende de la verdad de la proposición subordinada (de $p$ ), por lo que ésta puede ser falsa o expresar un contrasentido. El enunciado "A afirma que la nieve es verde" es verdadero, si en efecto "A" lo afirma, aunque la proposición subordinada "La nieve es verde" se verifique como falsa en numerosas ocasiones. Del mismo modo, el enunciado performativo de carácter prescriptivo: "Yo ordeno que $p$ y no $p$ ", recoge una contradicción entre las proposiciones subordinadas, pero es verdadero si, efectivamente, yo lo ordeno.

En el caso de las prescripciones (imperativos y normas), la proposición principal suele ser verdadera (lo veremos al hablar del valor de verdad de los enunciados performativos, en el punto 3), aunque la proposición subordinada no es ni verdadera ni falsa, hasta el momento de su cumplimiento. Si la prescripción se cumple, la proposición subordinada será verdadera; si no se cumple, falsa. Así, el enunciado "Te ordeno que cierres la puerta" es verdadero con independencia de que el destinatario cierre la puerta (en cuyo caso cumple la orden, y hace que la proposición subordinada, consistente en que el destinatario cierra la puerta, sea verdadera) o no la cierre (en cuyo caso no cumple la orden, y hace que la proposición subordinada sea falsa). Pero nada de esto afecta al valor de verdad de la proposición principal. En consecuencia, son erróneos todos los intentos de explicar la verdad de imperativos y normas a partir de la verdad del contenido de la prescripción misma, esto es, de la

10 Asimismo, Von Wright considera que los prefijos deónticos (debido, permitido, prohibido) expresan actitudes proposicionales [Von Wright 2016 (1996), 25]. 
proposición subordinada. Incluimos aquí la propuesta de Hare de separar, en los imperativos, el elemento prescriptivo o neústico, y el elemento descriptivo o frástico, y de aplicar la lógica solo a este último (Hare 1949, 21-39; y 1952, 17-31); así como la propuesta de una lógica de la satisfacción o cumplimiento de los imperativos (Hofstadter y Mckinsey, 1939); o la aplicación a las normas de una lógica trivalente, que incluye los valores "verdadero", "falso" y "ni verdadero ni falso" (Mendonca 2013).

\section{El valor de verdad de los enunciados performativos.}

\subsection{La verificación de la verdad de los imperativos.}

La posición de Austin respecto al valor de verdad de las expresiones performativas o realizativas no es tan definitiva como parece a simple vista. En la primera conferencia de su obra Cómo hacer cosas con palabras, el autor dirá que en los casos de expresiones performativas "parece claro que expresar la oración (por supuesto que en las circunstancias apropiadas) no es describir ni hacer aquello que se diría que hago al expresarme así, o enunciar que lo estoy haciendo: es hacerlo. Ninguna de las expresiones mencionadas es verdadera o falsa; afirmo esto como obvio y no lo discutiré, pues es tan poco discutible como sostener que 'maldición' no es una expresión verdadera o falsa" [Austin 1982 (1962), 46]. Puesto que las expresiones performativas no pueden ser verdaderas o falsas, Austin considera que no son "enunciados" [1982 (1962), 53].

Sin embargo, en posteriores conferencias, la cuestión ya no es tan obvia, al difuminarse la distinción entre expresiones performativas y constatativas (lo que llamamos enunciados, porque describen algo y pueden ser verdaderos o falsos). En efecto, dice el autor que: "Quizás, en verdad, no hay una gran diferencia entre los enunciados y las expresiones realizativas" [1982 (1962), 95]. Esta es toda la diferencia, según Austin: "En el caso de las expresiones constatativas, hacemos abstracción de los aspectos ilocucionarios del acto lingüístico (y, por supuesto, de sus aspectos perlocucionarios), y nos concentramos en el aspecto locucionario". En cambio, "en el caso de las expresiones realizativas se concentra al máximo nuestra atención en la fuerza ilocucionaria, con abstracción de la dimensión relativa a la correspondencia con los hechos". [Austin 1982 (1962), 192-193]. Es decir, la diferencia está en el aspecto de la expresión en que fijamos nuestra atención. 
Podemos decir, en consecuencia, que las expresiones performativas son también enunciados, por cuanto tienen también un elemento locutivo al que no prestamos atención normalmente en la comunicación humana. En nuestra opinión las emisiones performativas no solo realizan acciones, es decir, actos de emisión, (Searle y Vanderveken 1985, 9), sino que, al mismo tiempo que las realizan, las describen. Como señala Searle: “Una persona que dice 'Yo (por la presente) prometo', no solamente promete, sino que dice que lo hace" [Searle 1994 (1969), 73]. En una obra posterior Searle dirá que las emisiones performativas "en virtud de su significado literal son enunciados con valores de verdad" (Searle 1989, 540).

Podemos decir que mediante estas expresiones performativas, no solo se hace algo sino que se describe lo que se hace ${ }^{11}$. En consecuencia, las expresiones performativas (también las de carácter directivo, como las que significan imperativos o normas) tienen un carácter bifronte: son actos de habla mediante los que hacemos algo y, al mismo tiempo, enunciados que describen lo que hacemos, es decir, que describen el propio acto de habla ${ }^{12}$.

Mientras que los enunciados asertivos o descriptivos son actos de habla que hacen referencia a un hecho o estado de cosas externo al propio enunciado, los enunciados performativos hacen referencia a un hecho lingüístico, a la emisión del propio enunciado, es decir, al propio acto de habla: describen la acción de emitir el enunciado dotado de su significado específico y de determinada fuerza ilocutiva.

Parafraseando a Tarski [1972 (1944),14], el enunciado: "Te ordeno que cierres la puerta" es verdadero si, y solo si, te ordeno que cierres la puerta, es decir, si el emisor del enunciado da al destinatario la orden de cerrar la puerta ${ }^{13}$. Dicho de otro modo, el enunciado: “¿Cierra la puerta!” es verdadero si, y solo si, te ordeno que cierres la puerta.

¿Cuál es el valor de verdad de un enunciado performativo? El enunciado E1 "Yo ordeno que cierres la puerta" hace referencia al hecho H consistente en la emisión del propio enunciado cuyo significado es “yo ordeno que cierres la puerta” (o “¡cierra la puerta!”, “ique cierres la puerta!”, u otro de significado

11 También Hilpinen considera que los imperativos y normas son enunciados perfomativos y, en cuanto tales, verdaderos; pero no explica por qué los enunciados performativos son verdaderos. Véase Hilpinen 2006, 229 y ss.

12 En este sentido, véase Bach 1975, 229; Bach y Harnish 1992.

13 Esta idea ya fue expuesta por Cresswell 1973, 230-235, citado por Peña 2006, 114-115. Asimismo, Peña (2006, 114) defiende que los enunciados performativos son verdaderos, y cita en el mismo sentido a Lewis (1972) y a Stampe (1975). Para Peña, en cuanto enunciados performativos, tanto los imperativos como las normas promulgadas son verdaderos $(2006,122)$. Su posición es muy similar a la aquí defendida. 
equivalente). Lo importante aquí es destacar que el verbo performativo "ordeno" hace referencia a un hecho concreto: la emisión de un enunciado con una determinada fuerza ilocutiva (la de una orden) y un contenido específico.

¿Cómo se verifica la verdad de la emisión del enunciado, esto es, de la orden dada, de la pregunta hecha, etc.? La verdad del enunciado performativo El se verifica por la existencia del propio enunciado. Pues todo enunciado o "signo proposicional" es un hecho ${ }^{14}$. Si el enunciado performativo existe, es que ha sido emitido. Y si ha sido emitido, entonces es verdadero. No se debe confundir verdad con validez - o con éxito- de un enunciado performativo (realmente de la orden o norma enunciada por éste), ni condiciones de verdad de un enunciado (correspondencia con un hecho o estado de cosas, en estos casos, la emisión del propio enunciado), con condiciones de veracidad (sinceridad del hablante) o con condiciones de validez (por ejemplo, que la orden proceda de la autoridad competente) $)^{15}$.

¿Significa lo que llevamos dicho que un enunciado performativo es siempre verdadero? Dicho de otro modo, ¿hay alguna diferencia entre el enunciado performativo E1: "Te ordeno que cierres la puerta" y el enunciado E2: "Este enunciado te ordena que cierres la puerta"? Al enunciado E2 lo podemos calificar impropiamente de "autorreferencial", porque no sólo hace referencia a sí mismo, sino también a quien lo lee o escucha. Desde el punto de vista de la verificación de la verdad de ambos enunciados no hay ninguna diferencia entre ellos.

Para verificar la verdad de un enunciado imperativo cualquiera $E$, es decir, de una orden específica dada (o de cualquier enunciado performativo) es preciso comprobar que se ha emitido el enunciado $E$, y para ello es suficiente con comprobar la existencia del enunciado $E$ (que contiene la orden dada). Porque si el enunciado existe, su existencia es prueba de que ha sido emitido.

En el caso de una prescripción directa, dada por un "yo" a un "tú" o a un "vosotros", como el enunciado E1: "Te ordeno que cierres la puerta", el hecho $\mathrm{H}$ de que el enunciado ha sido emitido es evidente, sobre todo si el propio receptor o destinatario del enunciado está presente en la escena y ha percibido la emisión del enunciado. En estos casos, la verdad del enunciado es tan evidente que no

14 Véase Wittgenstein 2010 (1922): párrafos 3.14 y 3.143. Asimismo, para los enunciados normativos, Yoshino 2015 (2009), párrafos 2.1.5 y 2.1.6, la misma idea se repite en los párrafos 3.2.2 y 3.2.3. Como "hecho institucional” lo califica Searle 1994 (1969), 60.

15 Sobre las condiciones que deben darse para que un acto de habla sea exitoso y no defectuoso, Searle 1994 (1969), 74- 75, Searle y Vanderveken 1985, 12 ss. 
precisa ser demostrada. Para explicar lo evidente podríamos decir: "Es verdad que te ordeno que cierres la puerta porque te lo estoy ordenando"16. La evidencia de la verdad del enunciado performativo queda oscurecida cuando usamos la expresión equivalente en forma imperativa: “¡Cierra la puerta!”. Aquí solo captamos el aspecto ilocutivo del enunciado, quedando eclipsado el aspecto locutivo. La cuestión de la verdad del enunciado se aclara, como venimos haciendo, al usar una expresión equivalente de carácter performativo.

Sin embargo, con independencia de la verdad del enunciado para el emisor "A", puede suceder que el destinatario o receptor "B" no perciba el enunciado, en cuyo caso realmente no lo recibe; o que, recibido, no lo comprenda, es decir, no capte su significado, por ejemplo, por haberse emitido en una lengua desconocida para él. Pero nótese que también el enunciado "autorreferencial" E2 precisa ser percibido y comprendido por su destinatario para ser verdadero. Y que este tipo de enunciado tampoco puede existir sin que alguien o algo lo haya emitido. Por tanto, el valor de verdad de un enunciado performativo y de un enunciado "autorreferencial" es exactamente el mismo, y se verifica del mismo modo. En consecuencia, los enunciados E1 y E2 son equivalentes. En ambos casos, es el propio enunciado el que se presenta a sí mismo como hecho perceptible. Su verdad es evidente.

Incluso en el caso de las prescripciones directas, si no ha habido una percepción directa de la emisión del enunciado por parte del destinatario (y esto sucede cuando media cierto intervalo temporal entre la emisión y la percepción del enunciado), entonces se hace preciso comprobar que el enunciado ha sido emitido, y su emisión se verifica por la existencia del propio enunciado que, como evento del mundo, ha quedado registrado de algún modo.

Una prescripción directa es verdadera para el receptor, salvo que éste no haya percibido su emisión (con lo cual no la ha recibido), o no haya comprendido el significado del enunciado emitido (problemas de comprensión). Y esto es así con independencia de que quien da la orden no sea la autoridad competente para ello, o contradiga la orden de una autoridad superior, o no siga el procedimiento reglamentario establecido (problemas de validez) ${ }^{17}$; con independencia de que la orden haya sido

16 Por su parte Lorenzo Peña, desde el mismo punto de vista del emisor del enunciado performativo, sostiene que: "Quien dice preguntar, mandar, prometer o confesar algo lo está, de hecho, preguntando, mandando, prometiendo o confesando. Voy incluso más lejos que David Lewis, ya que sostengo que no se da dualidad alguna entre el uso auto-descriptivo y el performativo de 'Mando que se haga tal cosa'. Al constatar que lo mando, lo mando; y, al mandarlo, constato que lo mando" (Peña 2006, 122).

17 No parece que sean acertadas aquellas supuestas soluciones al dilema de Jørgensen que consisten o bien en el desarrollo de una lógica de la validez de las normas [Ross 1971 (1968)]; o bien en una semántica de mundos hipotéticos o posibles, en que se identifica la verdad 
revocada (derogada) posteriormente (problemas de vigencia); y con independencia de que quien recibe la orden no la cumpla (problemas de cumplimiento).

\subsection{La verificación de la verdad de las normas.}

La verificación de la verdad de las normas jurídicas escritas se realiza del mismo modo que para las prescripciones directas, comprobando la existencia del enunciado normativo cuyo significado es "Yo (la autoridad) ordeno p". Ahora bien, en el caso de las prescripciones directas la verdad de la orden dada es evidente cuando el receptor percibe, de manera directa e inmediata, la emisión del enunciado y lo comprende. En cambio, en el caso de las normas jurídicas positivas, al tratarse de prescripciones indirectas (dirigidas a “ellos"), y mediar cierto intervalo temporal (que puede ser considerable) entre la emisión del enunciado y la recepción por su destinatario, su verdad ya no es evidente.

Hay que determinar, antes que nada, que la norma es verdadera. Esto se comprueba constatando que el enunciado normativo (cuyo contenido o significado es la norma) ha sido emitido. Y una prueba de que fue emitido es que el enunciado normativo existe. Por tanto, para verificar la verdad de la norma, basta con confirmar la existencia del enunciado normativo cuyo significado es la norma. Esto se puede comprobar de muchas maneras, porque el enunciado normativo ha quedado registrado de muchas formas (en la memoria de los destinatarios de la norma, en los documentos escritos que recopilan normas, en informaciones sobre las normas a través de los medios de comunicación, etc.). Pero hay un registro, o publicación oficial del Estado, que permite conocer no solo que la norma es verdadera, esto es, que el enunciado normativo a que hace referencia existe, sino que es auténtica, es decir, que el enunciado normativo es exactamente el mismo que el que emitió la autoridad en su momento, que no ha sufrido ningún tipo de alteración.

Además, por razones de seguridad jurídica, el derecho presupone que la norma es conocida por los destinatarios, no desde el momento en que cada destinatario particular percibe el enunciado normativo, sino desde que la norma (el enunciado normativo) es publicada oficialmente.

\section{Normas verdaderas y relaciones lógicas entre normas.}

de la norma con su validez. Véase al respecto: Zuleta 2008, 70 y ss; Yoshino 2015 (2009), especialmente párrafos 2.3.2.4 a 2.3.2.8, y 3.5.3.2). 
En las relaciones lógicas entre normas, éstas son tomadas siempre como verdaderas (esto es, como realmente existentes, o válidas en la terminología de Kelsen $)^{18}$. Entonces, ¿cómo es posible que dos normas sean al mismo tiempo verdaderas y contradictorias entre sí? ¿No debería ser una verdadera y otra falsa?

Para responder a esta pregunta, es preciso recordar que las normas son expresiones performativas, y en cuanto tales, tienen un carácter bifronte: son al mismo tiempo actos de habla mediante los que se hace algo (actos de voluntad en la terminología de Kelsen) y enunciados que describen tales actos de habla.

Además, en cuanto enunciados, las normas son enunciados del tipo "A dice p". En consecuencia, una norma puede ser verdadera y contener un contrasentido. Por ejemplo: $\mathrm{O}\left(\mathrm{p}^{\wedge} \sim \mathrm{p}\right)$. Si esto es así, no es de extrañar que un mismo ordenamiento puedan coexistir dos normas verdaderas que sean contradictorias una con la otra.

En efecto, la contradicción entre normas no es más que el resultado de una deducción lógica, que da lugar a una norma deducida (derivada) autocontradictoria. Por ejemplo, en un mismo ordenamiento jurídico, tenemos la norma A que prescribe: "O (p)" y la norma B que dispone: "O $(\sim p)$ ”. De ambas normas podemos inferir la norma $\mathrm{C}$ (norma deducida o derivada, es decir, no promulgada) que establece " $\mathrm{O}\left(\mathrm{p}^{\wedge} \sim \mathrm{p}\right)$ ", y que contiene un contrasentido. La norma $\mathrm{C}$ es un enunciado del tipo "A dice $\mathrm{p}$ ", cuya verdad no depende de la verdad de las proposiciones subordinadas " $\mathrm{p} \wedge \sim \mathrm{p}$ ". De este modo se explica que en un mismo ordenamiento puedan coexistir dos normas verdaderas y contradictorias entre sí.

El problema surge en el momento de la aplicación de las normas contradictorias. Entonces la contradicción entre normas (incompatibilidad lógica) se convierte en una imposibilidad física (no se puede realizar y no realizar al mismo tiempo la misma conducta). Obviamente, la contradicción entre normas no desaparecerá por sí misma. Es preciso, entonces, resolver la contradicción lógica de acuerdo con los criterios de resolución de antinomias previstos en el propio ordenamiento. Estos criterios no son necesariamente lógicos, pero tienen como presupuesto una contradicción lógica entre enunciados normativos. 
Respecto de las relaciones lógicas entre normas o enunciados normativos, solo podemos dejar apuntadas algunas ideas. Como se pone de manifiesto en el ejemplo de arriba que explica la contradicción entre normas, las relaciones lógicas entre normas se expresan mediante la conjunción "y"19. En efecto, si tenemos dos normas promulgadas: $\mathrm{A}=O p, \mathrm{y} \quad \mathrm{B}=O q$, la consecuencia lógica de ambas es la norma derivada (no promulgada) $\mathrm{C}=O\left(p^{\wedge} q\right)$. El razonamiento lógico es el siguiente: $(O p$ $\wedge O q) \rightarrow O\left(p^{\wedge} q\right)$.

Podemos acudir también a la lógica de predicados, lo que nos permitirá explicar posteriormente la subsunción. (Puesto que presuponernos que las normas son generales, prescindimos de cuantificadores). Partimos del presupuesto de que las normas (y los enunciados performativos correspondientes a los imperativos) pueden ser reducidas a una estructura lógica condicional $(\rightarrow)$ o bicondicional ( $\leftrightarrow$ ) que une un supuesto de hecho (A) a una consecuencia jurídica (B). Es decir, la estructura lógica de una norma es siempre $A \rightarrow B, \mathrm{o} A \leftrightarrow B^{20}$. Incluso la norma más simple, como "p es obligatorio" (OP) puede ser expresada del siguiente modo: “si 'algo' consiste en P, entonces 'ese algo' es obligatorio (o, si se prefiere, “yo lo ordeno')". Es decir, Px $\rightarrow \mathrm{Ox}$. Convertimos de este modo el operador deóntico en un predicado.

La norma $O p$ se expresa como: $P x \rightarrow O x$. Y la norma $O q$ se expresa como: $Q y \rightarrow O y$. La consecuencia lógica de ambas normas es la norma: $(\mathrm{Px} \wedge \mathrm{Qy}) \rightarrow(\mathrm{Ox} \wedge \mathrm{Oy})$, que es una norma deducida, también llamada implícita o derivada. En efecto, el siguiente razonamiento es una tautología: $\left[(P x \rightarrow O x)^{\wedge}(Q y\right.$ $\rightarrow O y)] \rightarrow\left[\left(P x^{\wedge} Q y\right) \rightarrow\left(O x^{\wedge} O y\right)\right]$

Del mismo modo, si las normas no pudieran ser tomadas como enunciados (y no solo como meros actos de habla), no podría realizarse el silogismo jurídico de la subsunción, es decir, la obtención de una norma particular (la decisión del juez o aplicador del derecho), a partir de una norma general (premisa mayor) y de un enunciado fáctico (premisa menor). En efecto, la regla de la subsunción se explica como un supuesto de lo que en lógica de predicados se llama "la regla de instanciación universal", o "regla de eliminación del generalizador" (Garrido 2001, 180), que permite pasar de una regla general a un caso particular.

19 "El Derecho debe ser expresado a través de la combinación de los tipos de enunciados jurídicos previamente analizados. La combinación es representada a través de la conexión de enunciados jurídicos por medio del conectivo lógico de la 'conjunción', esto es, 'y”'. [Yoshino 2015 (2009), párrafo. 3.5.4.1).]

20 Son muchos los autores que conciben las normas como enunciados o juicios hipotéticos. Véase, por todos, García Máynez 1955 , 124 ss. 
Tomemos el enunciado normativo: "Se prohíbe la tortura". O dicho de otro modo: "Si una conducta cualquiera expresada por la variable individual " $\mathrm{x}$ " consiste en torturar $(\mathrm{T})$, entonces esa conducta " $\mathrm{x}$ " está prohibida ( $\mathrm{V}$, de "vetar, prohibir"). Tenemos la premisa mayor, que es el enunciado normativo: $T x$ $\rightarrow V x$. Y tenemos la premisa menor, que es un enunciado sobre los hechos: $T a$, es decir, la conducta concreta expresada por la constante individual "a" consiste en torturar. Entonces, concluimos lógicamente que la conducta concreta "a" está prohibida: $V a$. El razonamiento completo es: $[(T x \rightarrow V x)$ $\wedge T a] \rightarrow V a$.

Ciertamente, la conversión de la conclusión obtenida en norma particular (decisión judicial) depende de la voluntad del juez, pero es fruto de una deducción lógica ${ }^{21}$. Depende de la libre voluntad del juez (y no del automatismo de una computadora) aplicar la conclusión obtenida, resultado de la deducción lógica, o apartarse de la misma, contraviniendo al mismo tiempo las reglas de la lógica y el principio de legalidad.

La existencia de normas implícitas, o deducidas lógicamente de otras promulgadas es posible porque las normas se toman como enunciados. Es cierto que las normas son también actos de voluntad que proceden de la autoridad, pero desde el momento en que se formulan, y tratándose de normas jurídicas, desde el momento en que existen jurídicamente, (esto es, desde que son insertadas en el ordenamiento jurídico mediante su publicación oficial ${ }^{22}$ ), se convierten en enunciados que se desprenden de la autoridad que las ordenó, y entonces es posible deducir lógicamente normas implícitas (o derivadas) a partir de las normas explícitas.

Las normas derivadas son normas verdaderas. Aunque no son percibidas por los sentidos, son captadas intelectualmente, mediante la deducción lógica. Están implícitas en las normas promulgadas. Así, de la norma promulgada: $P x \leftrightarrow O x$, deducimos la norma implícita: $\sim P x \rightarrow \sim O x$. O se deducen de las relaciones lógicas entre ellas (como en los ejemplos de arriba). Su existencia depende de la de las normas promulgadas. De modo que si la norma promulgada es expulsada del ordenamiento jurídico, la norma implícita en aquélla también desaparece.

21Véase, en contra, Kelsen 1988 (1965), 114.

22 Para la distinción entre existencia fáctica y existencia jurídica de una norma, Guastini 2016 (2014), 223. Para las distintas nociones sobre existencia de una norma, véase: Bulygin y Mendonca 2005, 62 ss. 


\section{Bibliografía.}

Alchourrón, C. E. y Bulygin, E.; Introducción a la metodología de las ciencias jurídicas y sociales, Buenos Aires: Editorial Astrea, 1987. (Original en inglés de 1971).

Austin, J. L..; ¿Cómo hacer cosas con palabras? Traducción de Genaro Carrió y Eugenio Rabosi, Barcelona, Editorial Paidós, 1982 (Original de 1962).

Bach, K. "Performatives Are Statements Too", en Philosophical Studies, 1975, 28, pp. 229-236, <https://doi.org/10.1007/BF00353970>.

Bach, K. y Harnish, R. M.; "How Performatives Really Work: A Reply to Searle”, en Linguistics and Philosophy, 1992, 15, pp. 93-110, <https://doi.org/10.1007/BF00635834>.

Bulygin, E. y Mendonca, D.; Normas y sistemas normativos, Madrid, Marcial Pons, 2005.

Cresswell, M. J; Logics and Languages, Methuen \& Co. Ltd., 1973.

García Máynez, E.; Lógica del juicio jurídico, México, Buenos Aires, Fondo de Cultura Económica, 1955.

Garrido, M.; Lógica simbólica, Madrid, Tecnos, 4ª edición, 2001.

Guastini, R.; La sintaxis del derecho. Traducción de Álvaro Núñez Vaquero. Madrid, Marcial Pons, 2016 (Versión italiana de 2014).

Hare, R. M.; "Imperatives sentences”, en Mind, 1949, 58, pp 21-39.

Hare, R. M.; The language of morals, Oxford, at the Clarendon Press, 1952.

Hilpinen, R.; "Norms, Normative Utterances, and Normative Propositions", en Análisis Filosófico, 2006, XXVI, 2, pp. 229241 .

Hofstadter, A. y McKinsey, J. C. C.; “On the Logic of imperatives”, en Philosophy of Sciences, 1939, 6, pp .446-457.

Jørgensen, J.; “Imperatives and Logic”, en Erkenntnis, 1938, 7, pp. 288-296.

Jørgensen, J.; “Imperativos y lógica”, en C. Alarcón Cabrera; “Imperativos y lógica en Jørgen Jørgensen”, en Isegoría, 1999, 20, pp. 207-215. (Original de 1938, en Theoria, 4: 183-190).

Kelsen, H.; "Derecho y Lógica”, en H. Kelsen y U. Klug, Normas jurídicas y análisis lógico, Traducción de Juan Carlos Gardella, Madrid, Centro de Estudios Constitucionales, 1988, pp. 92-120. (Original de 1965, en Forum, 12 y 13, pp. 421425 y pp. 495-500).

Kelsen, H.; Teoría general de las normas. Traducción de Hugo Carlos Delory Jacobs.Editorial México, Trillas, 1994 (Original de 1979).

Lewis, D.; “General Semantics”, en Davidson \& Harman (eds.), Semantics of Natural Language, Reidel, 1972, pp. 169-218.

Lyons, J.; Semantics, Volume 2. Cambridge University Press, 1977.

Mendonca, D., "Hacia una lógica con y sin valores de verdad. Una respuesta al dilema de Jørgensen”, en Analisi e Diritto, 2013, pp. 135-142.

Peña, L.; "Imperativos, preceptos y normas", en LOGOS. Anales del Seminario de Metafísica, 2006, 39, pp. 111-142.

Ross, A.; "Imperatives and Logic", en Theoria, 1941, 7, pp. 53-71.

Ross, A.; Lógica de las normas. Traducción de José S.P. Hierro, Madrid, Tecnos, 1977 (Original de 1968). 
Searle, J. R.; Actos de habla. Traducción de Luis. M. Valdés Villanueva.Editorial, Barcelona, Planeta-De Agostini, 1994 (Original de 1969).

Searle, J. R. y Vanderveken, D.; Foundations of Illocutionary Logic, Cambridge, Cambridge University Press, 1985.

Searle, J. R.; “How Performatives Work”, en Linguistics and Philosophy, 1989, 12, pp. 535-558.

Stampe, D. W.; "Meaning and Truth in the Theory of Speech Acts", en Peter Cole \& Jerry L. Morgan, Syntax and Semantics, vol. 3: Speech Acts, New York: Academic Press, 1975, pp. 1-40.

Tarski, A.; La concepción semántica de la verdad y los fundamentos de la semántica, Traducción de Emilio Colombo, Buenos Aires, Ediciones Nueva Visión SAIC, 1972, (Original de 1944, en Philosophy and Phenomenological Research, 4, pp. 341-375).

Tomasini Bassols, A.; Estudios sobre las filosofías de Wittgenstein, México, Plaza y Valdés Editores, 2003.

Von Wright, G. H.; “LLógica sin verdad?”, Doxa. Cuadernos de Filosofía del Derecho, 2016, 32, pp. 21-34., https://doi.org/10.14198/DOXA2016.39.02. Traducción de Pablo E. Navarro. Revisión a cargo de Jorge L. Rodríguez (Versión de 1996: «Logica senza verità», en A. A. Martino (ed.), Logica, Informatica, Diritto, Pisa: Servizio Editoriale Universitario, pp.38-58.).

Wittgenstein, L.; Tractatus logico-philosophicus. Traducción de Jacobo Muñoz e Isidoro Reguera, Madrid, Alianza Editorial, (Primera edición, quinta reimpresión), 2010 (Original de 1922).

Vranas, P. B. M.; "In Defense of Imperative Inference", Journal of Philosophical Logic, 2010, 39, pp. 59-71, DOI: https://doi.org/10.1007/s10992-009-9108-8.

Yoshino, H.; "Tractatus Logico-Juridicus. Sus fundamentos", en Derecho del Estado, 2015, 35, pp. 267-293. DOI: http://dx.doi.org/10.18601/01229893.n35.10. (Original de 2009).

Zuleta, H. R.; Normas y justificación. Una investigación lógica, Madrid, Marcial Pons, 2008. 